\title{
Cardiovascular changes during chronic hypertensive states
}

\author{
Dorota Drozdz • Kalina Kawecka-Jaszcz
}

Received: 7 April 2013 /Revised: 3 August 2013 / Accepted: 21 August 2013 /Published online: 12 September 2013

(C) The Author(s) 2013. This article is published with open access at Springerlink.com

\begin{abstract}
It is well established that elevated blood pressure constitutes a major risk factor for coronary heart disease, arrythmias, heart failure, cerebrovascular disease, peripheral artery disease and renal failure. Blood pressure level and the duration of arterial hypertension (HTN) impact target organ damage. Many studies in adults have demonstrated the role of antihypertensive therapy in preventing cardiovascular (CV) events. The so-called hard end-points, such as death, myocardial infarction (MI) or stroke, are rarely seen in children, but intermediate target organ damage, including left ventricular hypertrophy, increased intima-media thickness and microalbuminuria, is already detectable during childhood. The goal of antihypertensive treatment is to reduce the global risk of $\mathrm{CV}$ events. In the adult population stratification of $\mathrm{CV}$ risk is based on blood pressure level, risk factors, subclinical target organ damage and established CV and kidney disease. Increased CV risk begins early in the course of kidney disease, and $\mathrm{CV}$ diseases are the most frequent cause of morbidity and mortality in patients with chronic kidney disease (CKD). Children with CKD are especially prone to the long-term effects of $\mathrm{CV}$ risk factors, which result in high morbidity and mortality in young adults. To improve the outcome, pediatric and adult CKD patients require nephro- and cardioprotection.
\end{abstract}

Keywords Cardiovascular events $\cdot$ Hypertension · Hypertensive heart disease - Left ventricular hypertrophy · Stroke $\cdot$ Atherosclerosis

\footnotetext{
D. Drozdz $(\bowtie)$

Dialysis Unit, Jagiellonian University Medical College,

265 Wielicka Str., 30-663 Krakow, Poland

e-mail: dadrozdz@cm-uj.krakow.pl

K. Kawecka-Jaszcz

First Department of Cardiology and Hypertension,

Jagiellonian University Medical College,

17 Kopernika Str., 31-501 Krakow, Poland
}

\section{Introduction}

Hypertension (HTN) is currently the single most important contributor to death around the world - in both developed or developing regions [1]. Elevated blood pressure (BP) is a major risk factor for coronary heart disease, atrial fibrillation, heart failure, cerebrovascular disease, peripheral artery disease and renal failure. Worldwide, 7.6 million premature deaths ( $13.5 \%$ of all premature deaths) have been attributed to high BP. Of the major cardiovascular (CV) events, about $54 \%$ of all strokes and $47 \%$ of all ischemic heart disease cases can be attributable to high BP [2]. An analysis of 23 HTN trials that involved 193,424 adult patients showed a high rate of coronary heart disease (41.1\%), stroke (30\%) and heart failure (28.9\% of recorded major CV events) among the patient cohorts [3].

The prevalence of HTN increases in adult populations, mostly because of aging populations and lifestyle changes, but also due to the obesity epidemic. Population-based data from Europe and North America indicate that $30-45 \%$ of the adult general population suffers from HTN [4]. The observed increase of HTN prevalence in children and adolescents has been reported to be associated with obesity and lifestyle changes. An important aspect of long-term prognosis is the tracking phenomenon. Elevated BP and cholesterol levels and obesity in children or teenagers persist into adulthood and increase the risk for $\mathrm{CV}$ events later in life [5]. The increasing prevalence of HTN in children and adolescents should be a warning signal to pediatricians that they must focus on the late consequences of HTN. As shown by the data from the Healthcare Cost and Utilization Project Kids' Inpatient Database, the frequency of HTN-associated hospitalizations during the 10-year study period increased across all age groups [6]. The so-called hard end-points, such as death, myocardial infarction (MI) or stroke, are rarely seen in children, but intermediate target organ damage, including left ventricular hypertrophy (LVH), increased intima-media thickness (IMT) 
and microalbuminuria, is already detectable during childhood. The reasons for hospitalization also differ between adult and pediatric hypertensive populations. In children with HTN the most common second diagnoses are convulsive disorder, headache, obesity and lupus erythematosus [6].

Despite rapid progress in dialysis techniques and medications (e.g. erythropoietin and growth hormone therapy), CV mortality rates among the dialysis patient population remains very high. In their foundational work, Foley et al. showed that young dialyzed adults have the same CV mortality risk as subjects aged $>85$ years in the general population [7]. Such patients, as young adults who started renal replacement therapy (RRT) in childhood, are especially prone to increased CV mortality.

The prognostic significance of ambulatory BP measurements is higher than that of office BP in predicting CV events and target organ damage. In a study by Torffvit [8], type 2 diabetic adult patients who had not achieved the goal of a nighttime systolic BP (SBP) of $<140 \mathrm{~mm} \mathrm{Hg}$ had a 12.9-fold higher risk of developing MI, a 3.9-fold increased risk of uremia and a 2.7-fold increased risk of death than patients who had achieved this goal. In addition, those patients who did not reach the goal despite further treatment experienced more serious changes in the kidneys caused by diabetes. Lurbe et al. monitored 75 adolescents and young adults with diabetes type 1 and normal urinary albumin excretion at the baseline evaluation [9]. These authors found that the observed increase of SBP during sleep (from 109.9 to $114.9 \mathrm{~mm} \mathrm{Hg}$ ) preceded the development of microalbuminuria.

\section{CV risk stratification}

The European Society of Hypertension and the European Society of Cardiology have published the Guidelines for the Management of Arterial Hypertension. In adult populations the stratification of $\mathrm{CV}$ risk is based on BP level, risk factors, subclinical organ damage (SOD) and established CV disease (CVD) and kidney disease. The categories are clearly defined. The main risk factors include systolic and diastolic blood pressure (DBP) levels, age ( $m a n>55$ years, women $>65$ years), smoking, dyslipidemia, fasting plasma glucose of 5.6$6.9 \mathrm{mmol} / \mathrm{l}$, abnormal glucose tolerance test, abdominal obesity and family history of premature CVD (man at age $<55$ years, women at age $<65$ years). Despite the presence of one out of the major risk factors (HTN, hypercholesterolemia, smoking), the vast majority of young and middle-aged adults will not experience an adverse $\mathrm{CV}$ event. In contrast, an adult patient with HTN grade 1 or 2 and one to two risk factors has a moderate $\mathrm{CV}$ risk, while evidence of three or more risk factors, metabolic syndrome, SOD or diabetes stratifies the patient into the high risk group.
Risk stratification using the SCORE (the Systemic Coronary Risk Evaluation) Project risk charts is recommended for each adult hypertensive patient [10]. The SCORE risk charts can be used to estimate the 10-year risk of fatal CVD by gender, age, SBP, total cholesterol and smoking status. Risk charts based on SCORE were developed for both low- and high-risk countries. In individuals at low or moderate risk (SCORE 1-4 \%) the search for SOD is encouraged. Sehestedt et al. showed the role of detecting SOD in the estimation of CV risk [11]. In healthy subjects the assessment of SOD includes increased pulse wave velocity (a marker of increased arterial stiffness), presence of atherosclerotic plaques, increased urine albumin/creatinine ratio (a marker of vascular damage) and increased LV mass (LVM), which predicts CV death independent of SCORE [11].

The presence of an established CVD or renal disease carries a very high CV risk, even in patients with normal or high-normal BP. HTN is the main CV risk factor, however patients with chronic kidney disease (CKD) also have many other uremia-related risk factors, such as inflammation, oxidative stress, increased renin-angiotensin-aldosterone system (RAAS) activity, increased $\mathrm{Ca} \times \mathrm{P}$ product, hyperphosphatemia, hyperparathyroidism, decreased FetuinA, elevated asymmetric dimethylarginine plasma concentrations, fluid overload and anemia [12]. These risk factors are why patients with renal diseases in the adult population are considered to be at very high $\mathrm{CV}$ risk - even those with high normal BP. A panel of experts has included CKD among the eight high-risk pediatric diagnoses associated with premature CV risk. Moreover, intervention strategies for children with CKD should be similar to the secondary prevention guidelines for adults with established coronary disease [13].

This cluster of different risk factors multiplies the CV risk. The coexisting risk factors differ depending upon age. In a study by Flynn et al. involving a group of 351 children with HTN, $44 \%$ were obese. The authors reported that the hypertensive children under 6 years were less likely to be obese or to have elevated cholesterol than school-age children or adolescents, but they were more likely to have secondary HTN and a lower glomerular filtration rate (GFR) [14]. Wilson et al. [15] studied children with $\mathrm{CKD}$ and found that the incidence of different $\mathrm{CV}$ risk factors increased with increasing body mass index. The patient group in this study comprised obese children with HTN, dyslipidemia and abnormal glucose metabolism [15]. The prevalence of CV risk factors was very high in children on RRT. In a Turkish study $44 \%$ patients on peritoneal dialysis had uncontrolled HTN and $39 \%$ had dyslipidemia [16].

CKD as well as essential HTN and obesity/metabolic syndrome are characterized by enhanced activity of the RAAS and the sympathetic nervous system [17]. These systems not only regulate $\mathrm{BP}$ but also contribute to $\mathrm{CV}$ abnormalities.

HTN in adults is defined as a SBP of $>140 \mathrm{~mm} \mathrm{Hg}$ and/or a DBP of $>90 \mathrm{~mm} \mathrm{Hg}$ [4]. Evidence from randomized controlled 
trials demonstrates that treatment-induced reductions in BP are beneficial in patients with such BP values. A large number of observational studies have demonstrated that $\mathrm{CV}$ morbidity and mortality have a continuous relationship with both SBP and DBP [18]. In adults, each 20-mm Hg increase in SBP or $10-\mathrm{mm} \mathrm{Hg}$ increase in DBP doubles the death rates from stroke and other $\mathrm{CV}$ causes. A meta-analysis of individual data for one million adults revealed that the relationship between BP and vascular mortality decreases steeply downwards, at least as far as the normal SBP of $115 \mathrm{~mm} \mathrm{Hg}$ and DBP of $75 \mathrm{~mm} \mathrm{Hg}$.

In children, BP increases with age and body size. Normative values for defining HTN have been determined on the basis of BP measurements in a large reference population [19]. In that study, the cut-off point for detecting HTN in children was defined as the 95th percentile for gender, age and height. To date, there have been no multicenter long-term studies assessing the impact of childhood BP level on clinically apparent CV complications in adulthood. However, in youth a graded increase in SOD parameters [carotid IMT (cIMT), arterial stiffness, LVM index (LVMI) and decrease in diastolic function] from normotension to pre-HTN and to HTN, has been found [20].

\section{Hypertensive heart disease}

\section{Pathophysiology}

Hypertensive heart disease consists of both vascular and myocardial changes. Various mechanisms are responsible for hypertensive heart disease, including endothelial dysfunction and coronary arteriolar constriction causing ischemia of the myocardium, increased fibrosis, apoptosis and inflammatory changes $[21,22]$. A major role in structural remodeling of the heart is played by cardiomyocyte and vascular smooth muscle cell hypertrophy, the conversion of fibroblasts to myofibroblasts, expansion of interstitial and perivascular collagen and decreased intramyocardial capillary density. Biochemical stress via stretchactivated ion channels leads to the intracellular transmission of signals to the nucleus, thereby up-regulating hypertrophic gene expression.

Fibrosis of the myocardium is an important risk factor for arrhythmias. Interstitial fibrosis interferes with optimal cardiac electrical conduction which establishes favorable conditions for re-entry circuits. Rudolph et al. reported that $50 \%$ of their patients with HTN had myocardial fibrosis, measured as late gadolinium enhancement [23]. In contrast to coronary heart disease, these lesions were predominantly non-subendocardial. In another study, treatment with angiotensin converting enzyme (ACE)-inhibitor demonstrated the efficacy of blocking the RAAS in reducing myocardial fibrosis as estimated by endomyocardial biopsy with measurement of the left ventricle collagen volume fraction and myocardial hydroxyproline concentration [24].

A study involving 1,454 pediatric dialysis patients found that arrhythmias were the most common cardiac-related events in these patients (19.6\%) [25]. Valvular heart disease $(11.7 \%)$, cardiomyopathy $(9.6 \%)$, cardiac arrest $(3.0 \%)$ and cardiac death $(2.8 \%)$ constituted the other cardiac-related events. HTN doubled the risk of cardiac disease in this group. Despite the fact that echocardiography is recommended as a routine test to be performed in all hypertensive children [19], this test was only performed in one-third of the children.

HTN induces a compensatory thickening of the ventricular wall in an attempt to normalize wall stress, which results in concentric LVH, which in turn decreases LV compliance and LV diastolic filling, causing heart failure. Diastolic dysfunction develops in hypertensive patients even in the absence of LVH. Impaired isovolumic relaxation leads to decreased velocity of early diastolic filling. Doppler imaging of the mitral inflow is a simple, noninvasive and repeatable method of assessing LV diastolic filling. A low early/atrial (E/A) mitral flow velocity ratio confers an increased risk of $\mathrm{CV}$ events in Caucasian patients with essential HTN [26]. This risk increases by $21 \%$ for each 0.3 decrease of the age- and heart rate-adjusted $\mathrm{E} / \mathrm{A}$ ratio. Impaired $\mathrm{LV}$ diastolic function in children with CKD is shown in the study of Mitsnefes et al. [27]. In a study on children on dialysis, the indices of LV relaxation and LV compliance were found to be significantly associated with the LVMI. A reliable marker of diastolic dysfunction, namely, the ratio of early mitral inflow to peak early diastolic annular velocity measured by Tissue Doppler $\left(E / E^{\prime}\right)$, was increased in the dialyzed and transplanted children. The $E / E^{\prime}$ ratio was significantly higher in patients with elevated BP, indicating an association between HTN and diastolic dysfunction [28]. In a group of 110 children on peritoneal dialysis, LVMI as well as E/E' correlated positively with mean arterial pressure (MAP) and negatively with hemoglobin and albumin levels and diuresis [29].

\section{Left ventricular hypertrophy)}

Research conducted on adults and children has revealed that LVM is significantly determined by fat-free mass (FFM). To avoid any incorrect interpretation of results when body surface area in obese patients is used, it was suggested that height raised to an exponential power of 2.7 should be used as an equivalent of FFM. The Fourth Report recommends using a single cut-off point $\left(38 \mathrm{~g} / \mathrm{m}^{2.7}\right)$ to define LVH in children [30]. Khoury et al. performed M-mode echocardiography in 2,273 non-obese healthy children and established percentile charts for LVM and LVMI depending on sex and age. The 95th percentile for LVMI ranged from $80 \mathrm{~g} / \mathrm{m}^{2.7}$ for newborns to $40 \mathrm{~g} / \mathrm{m}^{2.7}$ for 11 year olds. These researchers recommended 
the identification of LVH based on the 95th percentile for LVMI in children under 9 years of age, and in older children the accepted cut-off point was an LVMI of $>40 \mathrm{~g} / \mathrm{m}^{2.7}$ in girls and LVMI of $>45 \mathrm{~g} / \mathrm{m}^{2.7}$ in boys [31]. Foster et al. demonstrated that the 95th percentile LVMI depends on the height distribution of the reference population and proposed LVMfor-height percentiles as a superior means of normalizing LVM for body size [32]. In young children, the correct diagnosis of LVH is difficult to arrive at due to the small reference samples and rapid changes in body size and heart mass. In $\mathrm{CKD}$, children suffer from growth retardation and body composition changes (malnutrition, overhydration). Borzych et al. proposed using height age instead of chronological age to calculate the LVMI [33].

LVH is an important SOD in hypertensive subjects and an independent $\mathrm{CV}$ risk factor both in children and adult populations [34]. In several studies the relationship between LVM and subsequent $\mathrm{CV}$ risk was found to persist after adjustment for traditional risk factors. In the MAVI study, LVH doubled the risk of $\mathrm{CV}$ events. The following events developed during follow-up in a group of uncomplicated subjects with essential HTN: sudden cardiac death, MI, stroke, transient ischemic attack, heart failure, new onset unstable angina, arterial occlusive disease and progressive renal failure [34].

Left ventricle geometry can be classified into four categories: normal geometry, concentric remodeling [normal LVM, increased relative wall thickness (RWT)], concentric hypertrophy (elevated LVM and RWT) and eccentric hypertrophy (elevated LVM and normal RWT) [35]. Adult patients with concentric remodeling and hypertrophy have the highest peripheral resistance, and those with eccentric hypertrophy have a supernormal cardiac index, thereby demonstrating the role of pressure and volume overload as mechanisms involved in developing LVH. Moreover, in the group with concentric remodeling, the highest peripheral resistance was accompanied by reduced LV end-diastolic dimension, which suggests that pressure overload is balanced by a decreased volume load. In adults, concentric hypertrophy was found to be associated with the highest risk of CVD. In concentric hypertrophy, the degree of impaired LV filling (left atrial afterload) increases with increases in LV stiffness, which results in an increase in the size and function of the left atrium.

Concentric and eccentric LVH have been detected in children with primary HTN and in various studies in patients with CKD at different stages of the disease [36-38]. In a group of 128 children on peritoneal dialysis followed by the International Pediatric Network (IPPN) Registry, SBP was significantly lower in children with normal cardiac geometry than in patients progressing to LVH or with persistent LVH [39]. In the multivariate analysis, obesity and HTN were independent risk factors for persistent or de novo LVH. In the study performed by Lurbe et al., LVH, defined as an LVMI of $>95$ th percentile, was detected only in patients with masked HTN and not in the normotensive controls [40]. In another study involving CKD patients, masked HTN (defined as normal clinical BP but elevated in ambulatory BP measurements) was also linked to a significant increase in the risk of LVH [41]. These results highlight the need for performing regular ambulatory BP measurements in children with CKD. As shown by the results of the Escape study, concentric LVH is connected with subclinical systolic dysfunction (impaired fractional shortening at the midwall level) in children with CKD [42].

The treatment of HTN can result in the regression of $\mathrm{LVH}$, as shown in the Life study [43], which also showed that losartan was more efficient than atenolol. In a meta-analysis by Fagard et al., the regression of LVM was significantly less with $\beta$ blockers $(9.8 \%)$ than with angiotensin receptor blockers (12.5\%) [44]. Another important finding from this metaanalysis was that all indices of systolic (LV fractional shortening and ejection fraction) and diastolic function (LV inflow ratio of early to late diastolic filling) improved in response to antihypertensive treatment. In children with $\mathrm{CKD}$, treatment with fixed high-dose ACE inhibition led to reduction in LVH prevalence and improvement in systolic function. The association between an increase in midwall fractional shortening and a reduction in BP has been discovered [45].

Prospective studies performed in adult hypertensive subjects have found that $\mathrm{LVH}$ regression is associated with risk reduction of major $\mathrm{CV}$ morbid events, such as stroke, $\mathrm{MI}, \mathrm{CV}$ death, atrial fibrillation, heart failure and even new-onset diabetes mellitus [46, 47].

\section{Heart failure}

In adults, HTN is a very important risk factor for coronary artery disease, arrhythmias (atrial and ventricular), MI and systolic heart failure (Fig. 1). The impact of HTN on developing systolic heart failure is well established, and research focus is currently directed towards diastolic heart failure.

The mechanisms underlying diastolic heart failure include abnormal matrix dynamics, altered myocyte cytoskeleton, impaired active relaxation and marked increase in fibrosis

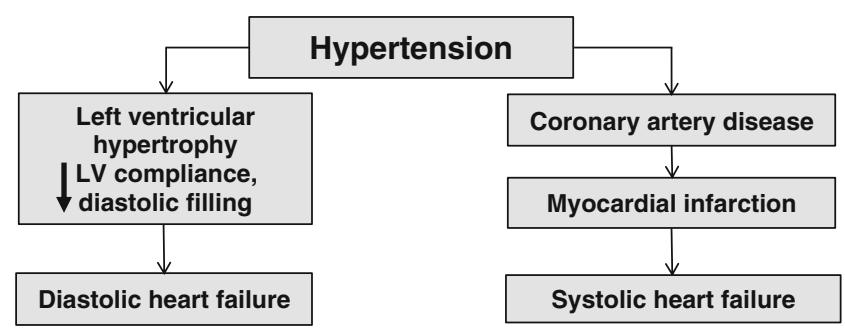

Fig. 1 In children, left ventricular $(L V)$ hypertrophy with decreased left ventricle compliance and diastolic dysfunction develops in the course of hypertension - it is the first asymptomatic stage of diastolic heart failure. In adults, hypertension is a main risk factor for coronary artery disease (myocardial infarction), which results in myocardial damage and systolic heart failure 
[48]. The stiffness of the left ventricle influences the volumepressure relationship during diastole, with small changes in $\mathrm{LV}$ volume resulting in a greater rise in pressure. Increased ventricular stiffness results from changes in extracellular matrix and cytoskeleton isoforms. An increase in activation of matrix metalloproteinases and tissue inhibitors of metalloproteinases can shift the type of collagen from type I to type III which has increased stiffness and cross-linking. Titin, a thick filament protein, is responsible for anchoring the thick filament to the z-disc in a sarcomere. Shifts to a stiffer isoform of titin (N2B) alter the properties of the myofilament cytoskeleton and contribute to ventricular stiffness. Ischemia and chronic conditions like diabetes with insulin resistance and increased free fatty acid flux are responsible for an abnormal energy balance in mitochondria and impaired removal of calcium during diastole by the sarcoplasmic/endoplasmic reticulum $\mathrm{Ca}^{2+}$ ATPase (SERCA2a) pump.

In the general population, the prevalence of congestive heart failure (CHF) and LV diastolic dysfunction increases with age [49]. Diastolic heart failure (DHF) accounts for more than $50 \%$ of the heart failure population and is also called heart failure with normal LV ejection fraction (LVEF). By definition, a patient with DHF presents the clinical signs and symptoms of heart failure (fatigue, dyspnea, reduced exercise tolerance, peripheral edema) with evidence of normal or mildly abnormal systolic LV function (LVEF $>50 \%$ ) and diastolic LV dysfunction [50]. In the Framingham Study HTN preceded the development of heart failure in $91 \%$ of patients and carried the greatest population-attributable risk for the development of CHF of all the risks considered [51]. In addition, HTN increased the risk of developing heart failure by about twofold in men and threefold in women. In hypertensive subjects MI, diabetes, LVH and valvular heart disease also increased the risk of CHF. The authors underlined the importance of preventive strategies directed toward earlier and aggressive $\mathrm{BP}$ control for reducing the incidence of $\mathrm{CHF}$ and its associated high mortality.

\section{Brain}

In adults, the brain is an early target for organ damage by elevated BP. HTN causes vascular brain injury directly [smallvessel disease (SVD)] or by promoting atherosclerosis or cardiac damage. HTN results in increased brain vascular resistance and the loss of the physiological mechanism of autoregulation. Hypertensive SVD is thought to be the main cause of silent brain infarcts, which, by definition, lack clinically overt stroke-like symptoms; rather, they are associated with subtle deficits in physical and cognitive function. Moreover, the presence of silent infarcts more than doubles the risk of subsequent stroke and dementia. In the adult population $75 \%$ of strokes occur in patients aged $>65$ years. In a study in
6,105 individuals with previous stroke or transient ischemic attack carried out by the PROGRESS Collaborative Group, combination therapy with perindopril and indapamid reduced systolic/diastolic BP by $12 / 5 \mathrm{~mm} \mathrm{Hg}$ and stroke risk by $43 \%$. A similar reduction in the risk of stroke in both hypertensive and non-hypertensive subgroups was found [52].

In children, ischemic and hemorrhagic strokes occur at an equally frequent rate, but their incidence is much lower than that in adults, namely 1.2 to 13 cases per 100,000 children under 18 years of age [53]. Clinical presentation in adolescents is similar to that in adults, it mimics another disease in younger children. The lack of awareness of a stroke in a child is responsible for the longer time to diagnosis this event in children than in adults, even in hospitalized patients. In adults, age is the most important non-modifiable risk factor and HTN the most important modifiable risk factor. The etiology of stroke in children is mostly multifactorial and varied: congenital and acquired heart disease, arteriovenous malformations and sickle cell disease, thrombophilias and infectious diseases such as varicella, sepsis, meningitis and even minor infection [54]. Arteriovenous malformations, cavernous malformations and aneurysms are the most common causes of pediatric hemorrhagic stroke. HTN is also counted among hemorrhagic stroke risk factors, yet since it rarely occurs in children it is considered to be a less important risk factor. The most sensitive method to diagnose acute ischemic stroke is brain magnetic resonance imaging, which requires sedation in younger children. Nephrologic pediatric patients with vasculitis are at a high risk of stroke. HTN, connective tissues diseases, a recent infection and/or migraine headaches increase the risk of vertebral artery dissection and cervical artery dissection, both of which are a common cause of strokes in young adults after injuries.

In children, an association has been reported between elevated SBP and reduced scores on the digit span test, which is a neuropsychological measure of attention and concentration [55]. Single-center studies provide preliminary evidence that hypertensive children manifest deficits on measures of neurocognition, have an increased prevalence of learning difficulties and have altered cerebrovascular reactivity (decreased ability to enhance cerebral blood flow in response to increased neuronal activity) [56, 57].

\section{Hypertension and vessels}

\section{Endothelial dysfunction}

Endothelial cells play an important role in vessel homeostasis and through their production of nitric oxide, prostacyclin and thrombomodulin they regulate vasodilatation and fibrinolysis and inhibit coagulation processes [58]. Both classic CV risk factors (HTN, smoking, diabetes, elevated low-density 
lipoprotein (LDL)-cholesterol level, chronic inflammation) and genetic factors influence endothelial function. The cumulative effects of these various factors on endothelial cells have led to the conclusion that endothelial function is a risk factor for the circulatory system [59]. Endothelial dysfunction is an early stage of atherosclerosis. Stimuli leading to vasorelaxation in the presence of intact vascular endothelium (such as acetylcholine) produce vasoconstriction when acting directly on the underlying smooth muscle cells in vascular areas with an injured endothelium [60]. Elevated BP causes mechanical injury to endothelial cells and concomitant endothelial dysfunction caused by other risk factors (hypercholesterolemia, uremiarelated risk factors) leads to vasoconstriction and to an increase in BP. A decrease in endothelium-dependent vasodilatation can be detected non-invasively by ultrasound imaging of the brachial artery. In the study performed by the Rostock group, decreased flow-mediated dilation of the brachial artery was observed in pediatric CKD patients and correlated with an early (preclinical) marker of atherosclerosis, increased cIMT [61].

\section{Atherosclerosis and vascular stiffness}

A broad spectrum of vascular pathology is observed in patients with CKD. The arterial wall thickness increases due to excessive pressure load, and different types of vascular calcification are present. Dysregulation of the calcium-phosphate-parathormone and vitamin $\mathrm{D}$ axis is thought to be the main mechanism of vascular calcification in children with CKD [62]. The central role in medial calcification is played by vascular smooth muscle cells (VSMC) influenced by promoters and inhibitors of calcification. Calcium- and phosphate-induced apoptosis and osteo/chondrocytic differentiation of VSMC, as well as increased deposition of VSMC-derived vesicles are found in vessel rings from CKD patients [63]. In in vitro conditions, elevated calcium is a more potent stimulus of calcification induction than elevated phosphate. It is mostly the medial calcification which causes arterial stiffness. In patients with normal vessel structure the reflected wave arrives back at the aortic root during diastole and increases coronary blood flow. Reflected waves are faster in stiff vessels, resulting in an increase in the central SBP and pulse pressure [64]. In adults, increased pulse wave velocity is counted among subclinical target organ damage. Intrafamilial heritability of various arterial stiffness indexes and MAP was demonstrated in the European Project on Genes in Hypertension (EPOGH) study that included 204 parents and 290 offspring [65].

Numerous studies have provided evidence that atherosclerosis begins in childhood and is associated with the same risk factors as in adults - obesity, HTN, dyslipidemia, diabetes mellitus, cigarette smoking. Berenson et al. carried out autopsy studies within the framework of The Bogalusa Heart Study and found that the early stages of atherosclerosis are already present in childhood [66]. The authors found fibrous plaque lesions and fatty streaks in the aortas and coronary arteries of persons aged 6-30 years and correlated these with antemortem risk factors. The lesions appeared earlier and were more advanced in men. This Swedish group also found more advanced peripheral artery involvement in boys, who had thicker intimal and medial wall layers in both the radial and dorsal pedal arteries [67].

Increased IMT marks early stages of atherosclerosis in children. In the patient cohort studied by Litwin et al., LVH was already present in $46 \%$ of patients with newly diagnosed primary HTN. A standard antihypertensive treatment lowered the BP and led to the regression of target organ damage as evidenced by decreased LVMI and decreased cIMT [68]. The association between cIMT and MAP, as well as highsensitivity $\mathrm{C}$-reactive protein in peritoneal dialyzed children has been reported. In this group of patients cIMT correlated negatively with hemoglobulin and albumin levels, and with $\mathrm{Kt} / \mathrm{V}$ urea [16].

In many multicenter studies in adults the efficacy of statin treatment in reducing the $\mathrm{CV}$ risk has been shown. Atherosclerosis risk factors, such as HTN, hypercholesterolemia and obesity, are already present in childhood, whereas their effects can be seen in adults. Population screening tests for hypercholesterolemia are recommended at the age of 9-11 and 17-19 years. If the family history shows either early occurrence of $\mathrm{CV}$ events in parents and grandparents, or if overweight, obesity, diabetes and/or HTN are present in a child, the lipid level should be tested at the age of 2 years. Studies carried out in children with familial hypercholesterolemia indicate the efficacy of statins in lowering the LDL-cholesterol level. The majority of statins are recommended for children aged $>10$ years, except for pravastatin (recommended for those aged $>8$ years).

Studies performed in children and in adults have demonstrated a significant role of HTN in the progression of CKD. However, different targets for BP control are recommended for children and adults. In the Escape study, performed in 385 children with $\mathrm{CKD}$, intensified BP control (MAP of $<50$ th percentile) improved renal survival, defined as the time to a $50 \%$ decline in the GFR or progression to end-stage renal disease (ESRD) [69]. In a large, community-based study (Kidney Early Evaluation Program: KEEP) covering adult participants with a GFR of $<60 \mathrm{ml} / \mathrm{min} / 1.73 \mathrm{~m}^{2}$, the risk of progression to ESRD started at a SBP of $140 \mathrm{~mm} \mathrm{Hg}$ and was highest among patients with a SBP of $\geq 150 \mathrm{~mm} \mathrm{Hg}$ [70]. In this group of 16,129 subjects, more than $33 \%$ of participants had uncontrolled HTN, mostly due to isolated systolic HTN. It has been suggested that the increased stiffness of the arteries of adult patients with CKD is responsible for the difficulties in treating HTN.

The recently published The Fifth Joint Task Force of the European Society of Cardiology and Other Societies on Cardiovascular Disease Prevention in Clinical Practice recommended preventive efforts should be life-long, from birth 
(if not before) to old age. Prevention has been shown to work: $>50 \%$ of the reductions seen in CHD mortality relate to changes in risk factors and $40 \%$ to improved treatments [10].

\section{Future considerations}

Long-term follow-up multicenter studies are necessary to assess CV risk stratification in children and adolescents with HTN and to develop standards for diagnostic and treatment procedures. An addition point which should also be examined is whether the application of screening tests for CV risk factors and the implementation of adequate treatment will result in a decrease of $\mathrm{CV}$ risk in adulthood. Randomized controlled trials are required to assess the safety and efficacy of different antihypertensive drugs in reducing SOD in children. Modern RRT results in lengthening the life expectancy of children and adolescents with ESRD. Coexistence of many traditional and uremia-related risk factors increases $\mathrm{CV}$ morbidity and mortality. New research to understand the impact of specific uremia-related factors on cardiac and vasculature remodeling/ injury is needed. Future studies to assess the efficacy and safety of statin treatment in different cases of secondary hypercholesterolemia, for example CKD and obesity, are needed.

\section{Summary}

Hypertension is currently the biggest single contributor to death around the world. Elevated BP represents an important risk factor for $\mathrm{CV}$ diseases, such as coronary heart disease, heart failure, stroke, peripheral artery disease and renal failure, in adults. It is well established that subclinical target organ damage (LVH, increased IMT, cognitive dysfunction, microalbuminuria) is already present in childhood. A special group of patients is that comprising children and adolescents with CKD. In observational and multicenter studies, subclinical target organ damage has been detected at early stages of CKD; however, regression and progression of LVH or IMT changes are possible. Ambulatory BP measurements and echocardiography should be performed in children with CKD on a regular basis in order to detect HTN and to monitor therapy. The results of the European Escape trial show that decreasing the BP to the low-normal range is associated with slowing the progression of CKD in children. The goal of antihypertensive treatment should not only be to normalize the BP but also to prevent target organ damage. The major concern in the management of hypertensive patients remains the heightened rate of late consequences.

The impact of HTN on CV damage has been extensively studied in large groups of adults - both in the general population and the adult CKD population. Based on observational and interventional studies, specific recommendations have been developed for the treatment of HTN and other risk factors (e.g. hypercholesterolemia) with the aim of reducing global CV risk. Long-term follow-up multicenter studies are necessary to assess CV risk stratification in children and adolescents with HTN and to work out standards for diagnostic and treatment procedures. New research to investigate the impact of specific uremia-related factors on cardiac and vasculature remodeling/injury are needed. The lack of comorbidities in children allows us to study the influence of HTN on early stages of organ damage - endothelial dysfunction in particular.

Children with $\mathrm{CKD}$ are at high risk of $\mathrm{CV}$ events, and preventive strategies should be started early in the course of renal disease.

\section{Questions (answers are provided following the reference list)}

1. The pathophysiological mechanisms leading to hypertensive heart disease are:

a. Interstitial and perivascular fibrosis

b. Myocardial ischemia

c. Changes in the extracellular matrix

d. All of the above

2. Which of the items listed below cannot be classified as subclinical target organ damage:

a. Left ventricular hypertrophy (LVH)

b. Increased intima media thickness (IMT)

c. Hemorrhagic stroke

d. Increased pulse wave velocity

3. For cardiovascular risk stratification in adults, which of the following are used;

a. Elevated blood pressure

b. Age

c. Glucose level

d. All of the above

4. In the general population:

a. Hypertension is the most important risk factor for global mortality

b. The increase of $20 \mathrm{~mm} \mathrm{Hg}$ in systolic blood pressure (BP) or $10 \mathrm{~mm} \mathrm{Hg}$ in diastolic DBP is associated with a doubling of cardiovascular risk

c. Target organ damage (LVH, increased IMT) is already present in childhood

d. All of the above are true

5. The most common cardiovascular disease in pediatric dialysis patients is:

a. Systolic heart failure

b. Diastolic heart failure

c. Arrhythmia

d. Cardiomyopathy 
Open Access This article is distributed under the terms of the Creative Commons Attribution License which permits any use, distribution, and reproduction in any medium, provided the original author(s) and the source are credited.

\section{References}

1. Ezzati M, Lopez AD, Rodgers A, Vander Horn S, Murray CJ, Comparative Risk Assessment Collaborating Group (2002) Selected major risk factors and global and regional burden of disease. Lancet 360:1347-1360

2. Lawes CM, Vander Hoorn S, Rodgers A, International Society of Hypertension (2008) Global burden of blood-pressure-related disease. Lancet 371:1513-1518

3. Tocci G, Sciarretta S, Volpe M (2008) Development of heart failure in recent hypertension trials. J Hypertens 26:1477-1486

4. Mancia G, Fagard R, Narkiewicz K, Redón J, Zanchetti A, Böhm M, Christiaens T, Cifkova R, De Backer G, Dominiczak A, Galderisi M, Grobbee DE, Jaarsma T, Kirchhof P, Kjeldsen SE, Laurent S, Manolis AJ, Nilsson PM, Ruilope LM, Schmieder RE, Sirnes PA, Sleight P, Viigimaa M, Waeber B, Zannad F, List of authors Task Force Members (2013) 2013 ESH/ESC guidelines for management of arterial hypertension. The Task Force for the management of arterial hypertension of the European Society of Hypertension (ESH) and of the European Society of Cardiology (ESC). J Hypertens 31:12811357

5. Sun SS, Grave GD, Siervogel RM, Pickoff AA, Arslanian SS, Daniels SR (2007) Systolic blood pressure in childhood predicts hypertension and metabolic syndrome later in life. Pediatrics 119: 237-246

6. Tran CL, Ehrmann BJ, Messer KL, Herreshoff E, Kroeker A, Wickman L, Song P, Kasper N, Gipson DS (2012) Recent trends in healthcare utilization among children and adolescents with hypertension in the United States. Hypertension 60:296-302

7. Foley RN, Parfrey PS, Sarnak MJ (1998) Clinical epidemiology of cardiovascular disease in chronic renal disease. Am J Kidney Dis 32: $112-119$

8. Torffvit O (2012) The effect of achieving a systolic blood pressure of $140 \mathrm{mmHg}$. A prospective study of ambulatory measurements in type 2 diabetic patients with nephropathy. J Diab Compl 26:540-545

9. Lurbe E, Redon J, Kesani A, Pascual JM, Tacons J, Alvarez V, Batlle D (2002) Increase in nocturnal blood pressure and progression to microalbuminuria in type 1 diabetes. N Engl J Med 347:797-805

10. The Fifth Joint Task Force of the European Society of Cardiology and Other Societies on Cardiovascular Disease Prevention in Clinical Practice (2012) European Guidelines on cardiovascular disease prevention in clinical practice (version 2012). Eur Heart J 33:1635-1701

11. Sehestedt T, Jeppesen J, Hansen TW, Wachtell K, Ibsen H, TorpPetersen C, Hildebrandt P, Olsen MH (2010) Risk prediction is improved by adding markers of subclinical organ damage to SCORE. Eur Heart J 31:883-891

12. Patel HP (2010) Early origins of cardiovascular disease in pediatric chronic kidney disease. Ren Fail 32:1-9

13. Expert Panel on Integrated Guidlines for Cardiovascular Health and Risk Reduction in Children and Adolescents (2011) Expert panel on integrated guidelines for cardiovascular health and risk reduction in children and adolescents. Pediatrics 128:213-256

14. Flynn J, Zhang Y, Solar-Yohay S, Shi V (2012) Clinical and demographic characteristics of children with hypertension. Hypertension 60:1047-1054

15. Wilson AC, Schneider MF, Cox C, Greenbaum LA, Saland J, White CT, Furth S, Warady BA, Mitsnefes MM (2011) Prevalence and correlates of multiple cardiovascular risk factors in children with chronic kidney disease. Clin J Am Soc Nephrol 6:2759-2765
16. Bakkaloglu SA, Saygili A, Sever L, Noyan A, Akman S, Ekim M, Aksu N, Doganay B, Yildiz N, Duzova A, Soylu A, Alpay H, Sonmez F, Civilibal M, Erdem S, Kardelen F (2009) Assessment of cardiovascular risk in paediatric peritoneal dialysis patients: a Turkish Pediatric Peritoneal Dialysis Study Group (TUPEPD) report. Nephrol Dial Transplant 24:3525-3532

17. Blankestijn PJ, London G, Fliser D, Jager KJ, Lindholm B, Goldsmith D, Wiecek A, Suleymanlar G, Agarwal R, Oritz A, Massy Z, Martinez-Castelao A, Covic A, Dekker FW, Zoccali C (2011) Major pathways of the reno-cardiovascular link: the sympathetic and renin-angiotensin systems. Kidney Int Suppl 1:13-16

18. Prospective Studies Collaboration (2002) Age-specific relevance of usual blood pressure to vascular mortality: a meta-analysis of individual data for one million adults in 61 prospective studies. Lancet 360:1903-1913

19. Lurbe E, Cifkova R, Cruickshank JK, Dillon MJ, Ferreira I, Invitti C, Kuznetsova T, Laurent S, Mancia G, Morales-Olivas F, Rascher W, Redon J, Schaefer F, Seeman T, Stergiou G, Wuehl E, Zanchetti A (2009) Management of high blood pressure in children and adolescents: recommendations of the European Society of Hypertension. J Hypertens 27:1719-1724

20. Urbina EM, Khoury PR, McCoy C, Daniels SR, Kimball TR, Dolan LM (2011) Cardiac and vascular consequences of pre-hypertension in youth. J Clin Hypertens 13:332-342

21. Frohlich ED (2009) An updated concept of left ventricular hypertrophy risk in hypertension. Ochsner J 9:181-190

22. Raman SV (2010) The hypertensive heart. J Am Coll Cardiol 55:91-96

23. Rudolph A, Abdel-Aty H, Bohl S, Boye P, Zagrosek A, Dietz R, Schultz-Menger J (2009) Noninvasive detection of fibrosis applying contrast-enhanced cardiac magnetic resonance in different forms of left ventricular hypertrophy. J Am Coll Cardiol 53:284-291

24. Brilla CG, Funck RC, Rupp H (2000) Lisinopril-mediated regression of myocardial fibrosis in patients with hypertensive heart disease. Circulation 102:1388-1393

25. Chavers BM, Li S, Collins AJ, Herzog CA (2002) Cardiovascular disease in pediatric chronic dialysis patients. Kidney Int 62:648-653

26. Schillaci G, Pasqualini L, Verdecchia P, Vaudo G, Marchesi S, Porcellati C, de Simone G, Mannarino E (2002) Prognostic significance of left ventricular diastolic dysfunction in essential hypertension. J Am Coll Cardiol 39:2005-2011

27. Mitsnefes MM, Kimball TR, Border WL, Witt SA, Glascock BJ, Khoury PR, Daniels SR (2004) Impaired left ventricular diastolic function in children with chronic renal failure. Kidney Int 5:14611466

28. Harkel ADJT, Cransberg K, Van Osch-Gevers M, Nauta J (2009) Diastolic dysfunction in paediatric patients on peritoneal dialysis and after renal transplantation. Nephrol Dial Transplant 24:1987-1991

29. Bakkaloglu SA, Saygili A, Sever L, Aksu N, Noyan A, Akman S, Ekim M, Dogany B, Yildiz N, Akalin F, Caliskan S, Kara OD, Duzova A, Soylu A, Atalay S (2010) Impact of peritoneal transport characteristics on cardiac function in paediatric peritoneal dialysis patients: a Turkish Pediatric Peritoneal Dialysis Study Group (TUPEPD) report. Nephrol Dial Transplant 25:2296-2303

30. National High Blood Pressure Education Program Working Group on High Blood Pressure in Children and Adolescents (2004) The fourth report on the diagnosis, evaluation and treatment of high blood pressure in children and adolescents. Pediatrics 114:555-557

31. Khoury PR, Mitsnefes M, Daniels SR, Kimball TR (2009) Agespecific reference intervals for indexed left ventricular mass in children. J Am Soc Echocardiogr 22:709-714

32. Foster BJ, Mackie AS, Mitsnefes M, Ali H, Mamber S, Colan SD (2008) A novel method of expressing left ventricular mass relative to body size in children. Circulation 117:2769-2775

33. Borzych D, Bakkaloglu SA, Zaritsky J, Suarez A, Wong W, Ranchin B, Qi C, Szabo AJ, Coccia PA, Harambat J, Mitu F, Warady BA, Schaefer F, International Pediatric Peritoneal Dialysis Network 
(2011) Defining left ventricular hypertrophy in children on peritoneal dialysis. Clin J Am Soc Nephrol 6:1934-1943

34. Verdecchia P, Carini G, Circo A, Dovellini E, Giovanninin E, Lombardo M, Solinas P, Gorini M, Maggioni AP, MAVI Study Group (2001) Left ventricular mass and cardiovascular morbidity in essential hypertension: the MAVI Study. J Am Coll Cardiol 38:1829-1835

35. Ganau A, Devereux RB, Roman MJ, de Simone G, Pickering TG, Saba PS, Vargiu P, Simongini I, Laragh JH (1992) Patterns of left ventricular hypertrophy and geometric remodeling in essential hypertension. J Am Coll Cardiol 19:1550-1558

36. Richey PA, DiSessa TG, Somes GW, Alpert BS, Jones DP (2010) Left ventricular geometry in children and adolescents with primary hypertension. Am J Hypertens 23:24-29

37. Johnstone LM, Jones CL, Grigg LE, Wilkinson JL, Walker RG, Powell HR (1996) Left ventricular abnormalities in children, adolescents and young adults with renal disease. Kidney Int 50: 998-1006

38. Drozdz D, Kordon Z, Pietrzyk JA, Drozdz M, Rudzinski A, Zachwieja K (2008) The assessment of heart function in children with chronic kidney disease (CKD). Pol Merkur Lekarski 24[Suppl 4]:98-100

39. Bakkaloglu SA, Borzych D, Ha IS, Serdaroglu E, Buescher R, Salas P, Patel H, Drozdz D, Vondrak K, Watanabe A, Villagra J, Yavascan O, Valenzuela M, Gipson D, Ng KH, Warady BA, Schaefer F, for the International Pediatric Network (2011) Cardiac geometry in children receiving peritoneal dialysis: finding from the International Pediatric Network. Clin J Am Soc Nephrol 6:1926-1933

40. Lurbe E, Torro I, Alvarez V, Nawrot T, Paya R, Redon J, Staessen JA (2005) Prevalence, persistence, and clinical significance of masked hypertension in youth. Hypertension 45:493-498

41. Mitsnefes M, Flynn J, Cohn S, Samuels J, Blydt-Hansen T, Saland J, Kimball T, Furth S, Warady B, CKiD Study Group (2010) Masked hypertension associates with left ventricular hypertrophy in children with CKD. J Am Soc Nephrol 21:137-144

42. Chinali M, de Simone G, Matteucci MC, Picca S, Mastrostefano A, Anarat A, Caliskan S, Jeck N, Neuhaus TJ, Peco-Antic A, Peruzzi L, Testa S, Mehls O, Wuehl E, Schaefer F, ESCAPE Trial Group (2007) Reduced systolic myocardial function in children with chronic renal insufficiency. J Am Soc Nephrol 18:593-598

43. Devereux RB, Dahlof B, Gerdts E, Boman K, Nieminen MS, Papademetriou V, Rokkedal J, Harris KE, Edelmen JM, Wachtell K (2004) Regression of hypertensive left ventricular hypertrophy by losartan compared with atenolol: the Losartan Intervention for Endpoint Reduction in Hypertension (LIFE) Trial. Circulation 110: 1456-1462

44. Fagard RH, Celis H, Thijs L, Wouters S (2009) Regression of left ventricular mass by antihypertensive treatment. A meta-analysis of randomized comparative studies. Hypertension 54:1084-1091

45. Matteucci MC, Chinali M, Rinelli G, Wuehl E, Zurowska A, Charbit M, Pongiglione G, Schaefer F, ESCAPE Trial Group (2013) Change in cardiac geometry and function in CKD children during strict BP control: a randomized study. Clin J Am Soc Nephrol 8:203-210

46. Devereux RB, Wachtell K, Gerdts E, Boman K, Nieminem MS, Papademetriou V, Rokkedal J, Harris K, Aurup P, Dahlof B (2004) Prognostic significance of left ventricular mass change during treatment of hypertension. JAMA 292:2350-2356

47. Schillaci G, Pirro M, Mannarino E (2007) Left ventricular hypertrophy reversal and prevention of diabetes? Two birds with one stone? Hypertension 50:851-853

48. Wood P, Piran S, Liu PP (2011) Diastolic heart failure: progress, treatment challenges, and prevention. Can J Cardiol 27:302-310

49. Kloch-Badelek M, Kuznetsova T, Sakiewicz W, Tikhonoff V, Ryabikov A, Gonzalez A, Lopez B, Thijs L, Jin Y, Malyutina S, Stolarz-Skrzypek K, Casiglia E, Diez J, Narkiewicz K, KaweckaJaszcz K, Staessen JA (2012) Prevalences of left ventricular diastolic dysfunction in European populations based on cross-validated diagnostic thresholds. Cardiovasc Ultrasound 10:1-9

50. Paulus WJ, Tschope C, Sanderson JE, Rusconi C, Flachskampf FA, Rademakers FE, Marino P, Smiseth OA, Keulenaer GD, LeiteMoreira AF, Borbely A, Edes I, Handoko ML, Heymans S, Pezzali N, Pieske B, Dickstein K, Fraser AG, Brutsaert DL (2007) How to diagnose diastolic heart failure: a consensus statement on the diagnosis of heart failure with normal left ventricular ejection fraction by the Heart Failure and Echocardiography Associations of the European Society of Cardiology. Eur Heart J 28:2539-2550

51. Levy D, Larson MG, Vasan RS, Kannel WB, Ho KKL (1996) The progression from hypertension to congestive heart failure. JAMA 275:1557-1562

52. PROGRESS Collaborative Group (2001) Randomised trial of a perindopril-based blood-pressure-lowering regimen among 6105 individuals with previous stroke or transient ischaemic attack. Lancet 358:1033-1041

53. Tsze DS, Valente JH (2011) Pediatric stroke: a review. Emerg Med Int 2011: Article ID 734506

54. Jordan LC, Hillis AE (2011) Challenges in the diagnosis and treatment of pediatric stroke. Nat Rev Neurol 7:199-208

55. Lande MB, Kaczorowski JM, Aunger P, Schwartz GJ, Weitzman M (2003) Elevated blood pressure and decreased cognitive function among school-age children and adolescents in the United States. J Pediatr 143:720-724

56. Adams HR, Szilagyi PG, Gebhardt L, Lande MB (2010) Learning and attention problems among children with pediatric primary hypertension. Pediatrics 126:1425-1429

57. Lande MB, Kupferman JC, Adams HR (2012) Neurocognitive alterations in hypertensive children and adolescents. J Clin Hypertens 14: 353-359

58. Endemann DH, Schiffrin EL (2004) Endothelial dysfunction. J Am Soc Nephrol 15:1983-1992

59. Chlopicki S, Gryglewski RJ (2005) Angiotensin converting enzyme (ACE) and hydroxymethylglutaryl-CoA (HMG-CoA) reductase inhibitors in the forefront of pharmacology of endothelium. Pharmacol Rep 57[Suppl]:86-96

60. Tousoulis D, Antoniades C, Stefanadis C (2005) Evaluating endothelial function in humans: a guide to invasive and non-invasive techniques. Heart 91:553-558

61. Muscheites J, Meyer AA, Drueckler E, Wigger M, Fischer D-C, Kundt G, Kienast W, Haffner D (2008) Assessment of the cardiovascular system in pediatric chronic kidney disease: a pilot study. Pediatr Nephrol 23:2233-2239

62. Shroff R, Quinlan C, Mitsnefes M (2011) Uraemic vasculopathy in children with chronic kidney disease: prevention or damage limitation? Pediatr Nephrol 26:853-865

63. Shroff RC, McNair R, Skepper JN, Figg N, Schurgers LJ, Deanfield J, Rees L, Shanahan CM (2010) Chronic mineral dysregulation promotes vascular smooth muscle cell adaptation and extracellular matrix calcification. J Am Soc Nephrol 21:103-112

64. London GM, Guerin AP (1999) Influence of arterial pulse and reflected waves on blood pressure and cardiac function. Am Heart J 138:220-224

65. Seidlerova J, Bochud M, Staessen JA, Cwynar M, Doljsova M, Kuznetsova T, Nawrot T, Plszanecka A, Stolarz K, Thijs L, Wojciechowska W, Struijker-Boudier HA, Kawecka-Jaszcz K, Elston RC, Fagard R, Filipovsky J (2008) Heritability and intrafamilial aggregation of arterial characteristics. J Hypertens 26:721-728

66. Berenson GS, Wattigney WA, Tracy RE, Newmann WP III, Srinivasan SR, Webber LS, Dalferes ER, Strong JP (1992) Atherosclerosis of the aorta and coronary arteries and cardiovascular risk factors in person aged 6 to 30 years and studied at necropsy (The Bogalusa Heart Study). Am J Cardiol 70:851-858

67. Osika W, Dangardt F, Montgomery SM, Volkmann R, Ming Gan L, Friberg P (2009) Sex differences in peripheral artery intima, media and 
intima media thickness in children and adolescents. Atherosclerosis 203:172-177

68. Litwin M, Niemirska A, Śladowska-Kozłowska J, Wierzbicka A, Janas R, Wawer ZT, Wisniewski A, Feber J (2010) Regression of target organ damage in children and adolescents with primary hypertension. Pediatr Nephrol 25:2489-2499

69. Wühl E, Trivelli A, Picca S, Litwin M, Peco-Antic A, Zurowska A, Testa S, Jankauskiene A, Emre S, Caldas-Afonso A, Anarat A, Niaudet P, Mir S, Bakkaloglu A, Enke B, Montini G, Wingen AM, Sallay P, Jeck N, Berg U, Caliskan S, Wygoda S, HohbachHohenfellner K, Dusek J, Urasinski T, Arbeiter K, Neuhaus T, Gellermann J, Drozdz D, Fischbach M, Möller K, Wigger M, Peruzzi L, Mehls O, Schaefer F, ESCAPE Trial Group (2009) Strict blood pressure control and progression of renal failure in children. $\mathrm{N}$ Engl J Med 361:1639-1650
70. Peralta CA, Norris KC, Li S, Chang TI, Tamura MK, Jolly SE, Bakris G, McCullough PA, Shlipak M, KEEP Investigators (2012) Blood pressure components and end-stage renal disease in persons with chronic kidney disease: the Kidney Early Evaluation Program (KEEP). Arch Intern Med $172: 41-47$

\section{Answers:}

1. d

2. c

3. d

4. d

5. c 